
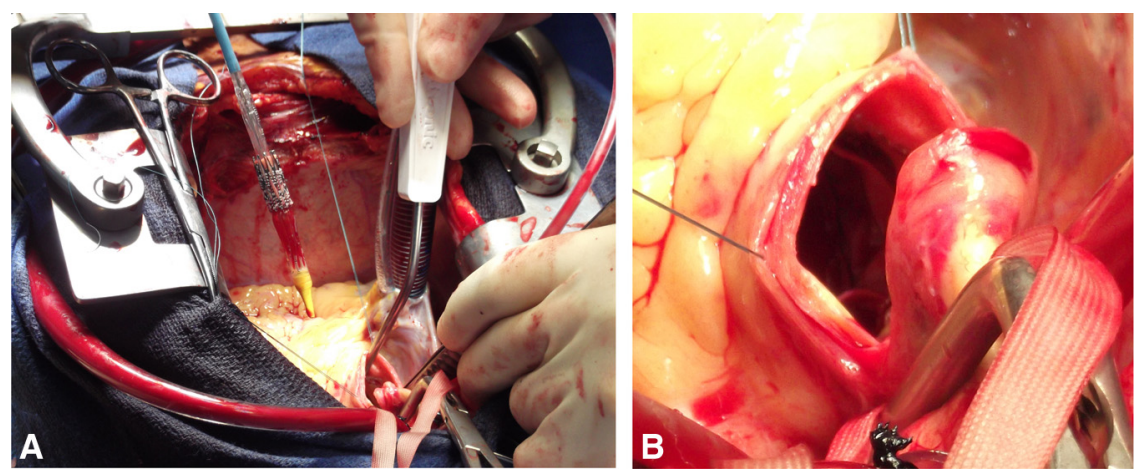

FIGURE 2. A, Image from head end showing aortotomy and transfemoral 26-mm Edwards Sapien TAVI valve being prepared for positioning under direct vision. B, Close-up view through aortotomy showing TAVI valve after successful deployment.

patients. $^{3}$ The combination of transaortic TAVI and coronary bypass surgery also has been reported. ${ }^{4} \mathrm{We}$ describe a case in which the extent of circumferential aortic calcification presented a considerable technical challenge for conventional aortic valve surgery, but in a patient in whom LAD disease also was believed to be very difficult to manage by percutaneous coronary intervention. It therefore was decided, given our familiarity with TAVI, that we should make use of the transfemoral TAVI valve and delivery system to replace the aortic valve at the same time the left internal thoracic artery to LAD was performed, thus avoiding the requirement for suturing at the level of the dense aortic calcification. The utility of a TAVI valve in this case highlights the potential in clinical practice for sutureless aortic valve prostheses.

\section{References}

1. Leon M, Smith C, Mack M, Miller DC, Moses JW, Svensson LG, et al. Transcatheter aortic-valve implantation for aortic stenosis in patients who cannot undergo surgery. N Engl J Med. 2010;363:1597-607.

2. Smith C, Leon M, Mack M, Miller DC, Moses JW, Svensson LG, et al. Transcatheter versus surgical aortic-valve replacement in high-risk patients. $N$ Engl J Med. 2011;364:2187-98.

3. Bapat V, Attia R, Thomas M. Distribution of calcium in the ascending aorta in patients undergoing transcatheter aortic valve implantation and its relevance to the transaortic approach. JACC Cardiovasc Interv. 2012;5:470-6.

4. Wiegerinck E, Cocchieri R, Baan J Jr, de Mol BA. Hybrid coronary artery bypass grafting and transaortic transcatheter aortic valve implantation. J Thorac Cardiovasc Surg. 2013;145:600-2.

\title{
Four-year follow-up after thoracic endovascular aortic repair for symptomatic thoracoabdominal aneurysm through the off-label use of a bifurcated abdominal endograft
}

\author{
Mario Marino, MD, Holta Kasemi, MD, Enrico Sbarigia, MD, and Francesco Speziale, MD, Rome, Italy
}

Thoracic endovascular aortic repair has become an alternative to the open surgical or to the hybrid approach for thoracoabdominal aortic aneurysm (TAAA) treatment. ${ }^{1}$ Fenestrated and branched endografts allow the exclusion

\footnotetext{
From the Vascular Surgery Unit, Department "Paride Stefanini," Sapienza University of Rome, Rome, Italy.

Disclosures: Authors have nothing to disclose with regard to commercial support.

Received for publication May 20, 2013; revisions received July 3, 2013; accepted for publication July 26, 2013; available ahead of print Sept 16, 2013.

Address for reprints: Holta Kasemi, MD, Vascular Surgery Unit, Department "Paride Stefanini", Sapienza University of Rome, Policlinico Umberto I, Viale del Policlinico 165, 00161, Rome, Italy (E-mail: kasemiholta@libero.it).

J Thorac Cardiovasc Surg 2013;146:e54-6

$0022-5223 / \$ 36.00$

Copyright (c) 2013 by The American Association for Thoracic Surgery

http://dx.doi.org/10.1016/j.jtcvs.2013.07.059
}

of the aneurysm and perfusion of the visceral arteries. Unfortunately, these devices require from 4 to 6 weeks for manufacture, an unsafely long wait for a symptomatic or ruptured TAAA. In an emergency setting, the use of offthe shelf devices of standardized design permits treatment of more than $80 \%$ of TAAAs. ${ }^{2}$ Homemade devices have been reported for urgent TAAA repair. ${ }^{3}$ In addition, the chimney and sandwich endovascular techniques remain a valid alternative for patients with symptomatic or ruptured TAAA.

We report the 4-year follow-up of a high-risk patient with symptomatic TAAA treated with an unusual endovascular technique: off-label use of a device manufactured for infrarenal aortic aneurysm repair. 


\section{CLINICAL SUMMARY}

A 69-year-old man in hemodynamically stable condition came to our emergency department with chest and back pain. His medical history revealed hypertension, chronic renal failure, chronic obstructive pulmonary disease, severe postischemic dilated cardiomyopathy (ejection fraction $18 \%$ ), and cardiac defibrillator use. Seven years previously, the patient had undergone a gastroduodenal artery embolization and gastroduodenal resection because of digestive tract bleeding.

Contrast-enhanced computed tomographic angiography demonstrated a TAAA $7 \mathrm{~cm}$ in diameter (Figure 1). The superior mesenteric artery (SMA) and the renal arteries originated from a healthy aortic portion. The proximal neck length of the infrarenal portion of the TAAA was $35 \mathrm{~mm}$ (aneurysmal diameter $8 \mathrm{~cm}$ ). Endovascular aneurysmal exclusion in the emergency setting was offered to the patient. Written, informed consent and institutional review board approval were obtained before the procedure.

With local anesthesia, after systemic heparinization and through an open right femoral approach, a selective angiogram demonstrated no collateral supply of the celiac trunk. A bifurcated endograft (Endurant ENBF 3216C120; Medtronic Inc, Minneapolis, Minn) was deployed $7 \mathrm{~cm}$ distal to the left subclavian artery. The ipsilateral limb was extended to the celiac trunk with a straight endograft (Endurant ENLW 1610C95; Medtronic), and a covered stent-graft (Viabahn $11 \times 100 \mathrm{~mm}$; W. L. Gore and Associates Inc, Flagstaff, Ariz) was deployed subsequently through an open left subclavian access (Figure 2, A).

Through an open left femoral approach, the contralateral leg was extended with Endurant and Valiant endografts (ENLW 1628C80EE and VAMC 3232B100TE; Medtronic) just proximal to the SMA. Angiography showed a type $\mathrm{Ib}$ endoleak that needed a distal cuff deployment (Excluder 320400; Gore). The infrarenal portion of the aneurysm was treated with the Excluder endograft (PXT 311415, ipsilateral limb PXC 201000, contralateral limb PXL 161207, and PXC 201200; Gore).

The completion angiography demonstrated complete aneurysmal exclusion, with no signs of endoleak and with patency of the celiac trunk, SMA, and renal arteries. The procedure lasted 280 minutes, $180 \mathrm{~mL}$ contrast medium was administered, and the total fluoroscopy time was 117 minutes.

No difference between the upper and lower limb blood pressures caused by a coarctation similar to the congenital coarctation due to the endografts deployed in the thoracic portion was registered. No variation of the liquor pressure was observed. The postoperative course was

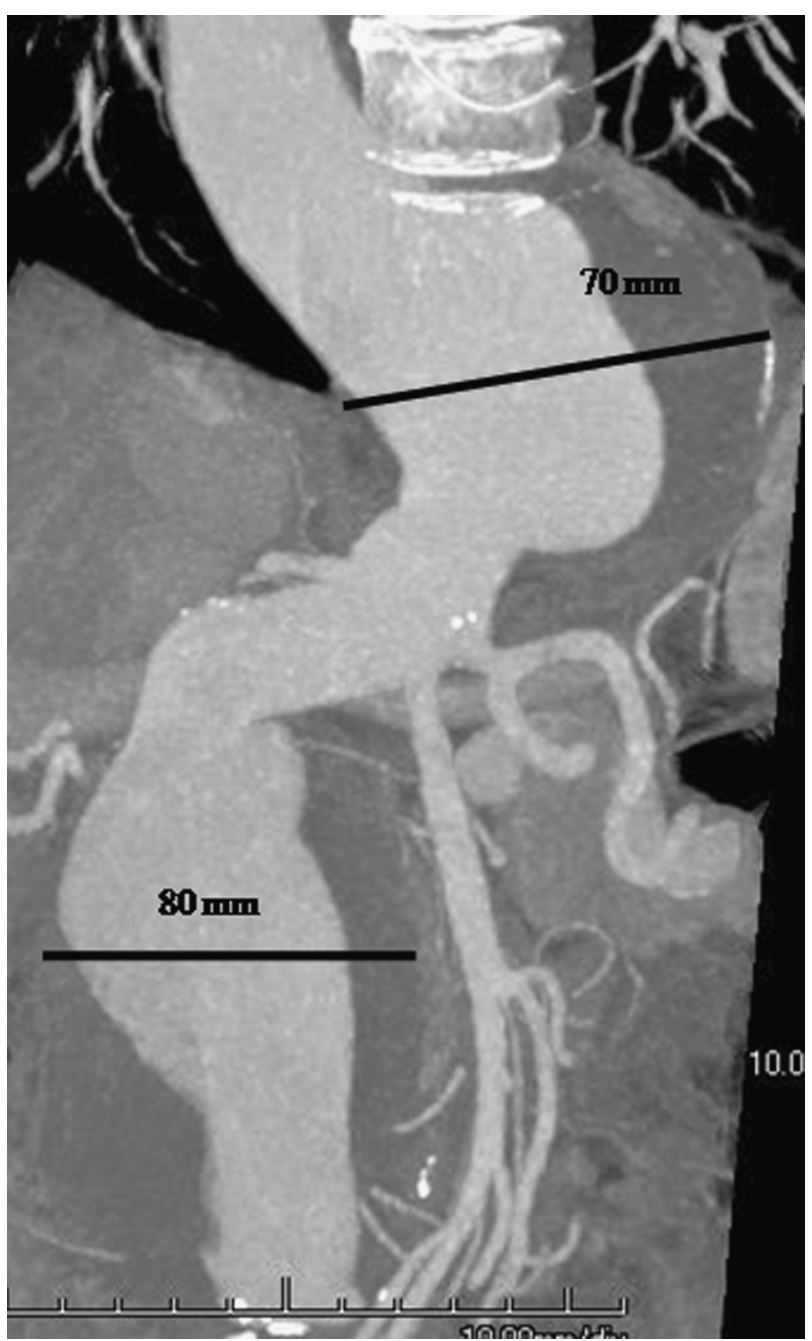

FIGURE 1. Preoperative computed tomographic scan.

uneventful, and the patient was discharged on the fifth postoperative day with oral antiplatelet therapy (aspirin at $100 \mathrm{mg} / \mathrm{d}$ ).

The patient underwent computed tomographic scan control at 1 month follow-up and yearly thereafter. The 4-year follow-up computed tomographic scan confirmed complete aneurysmal exclusion, with no signs of endoleak and complete visceral vessel patency (Figure 2, B).

\section{DISCUSSION}

Surgical or hybrid TAAA repair was not feasible in our case because of the patient's comorbidities and the absence of collateral supply of the celiac trunk from the SMA. Moreover, custom device manufacture required too much time, and at the time we did not have enough experience with homemade devices. A chimney or periscope technique was not performed because thoracic endograft oversizing 


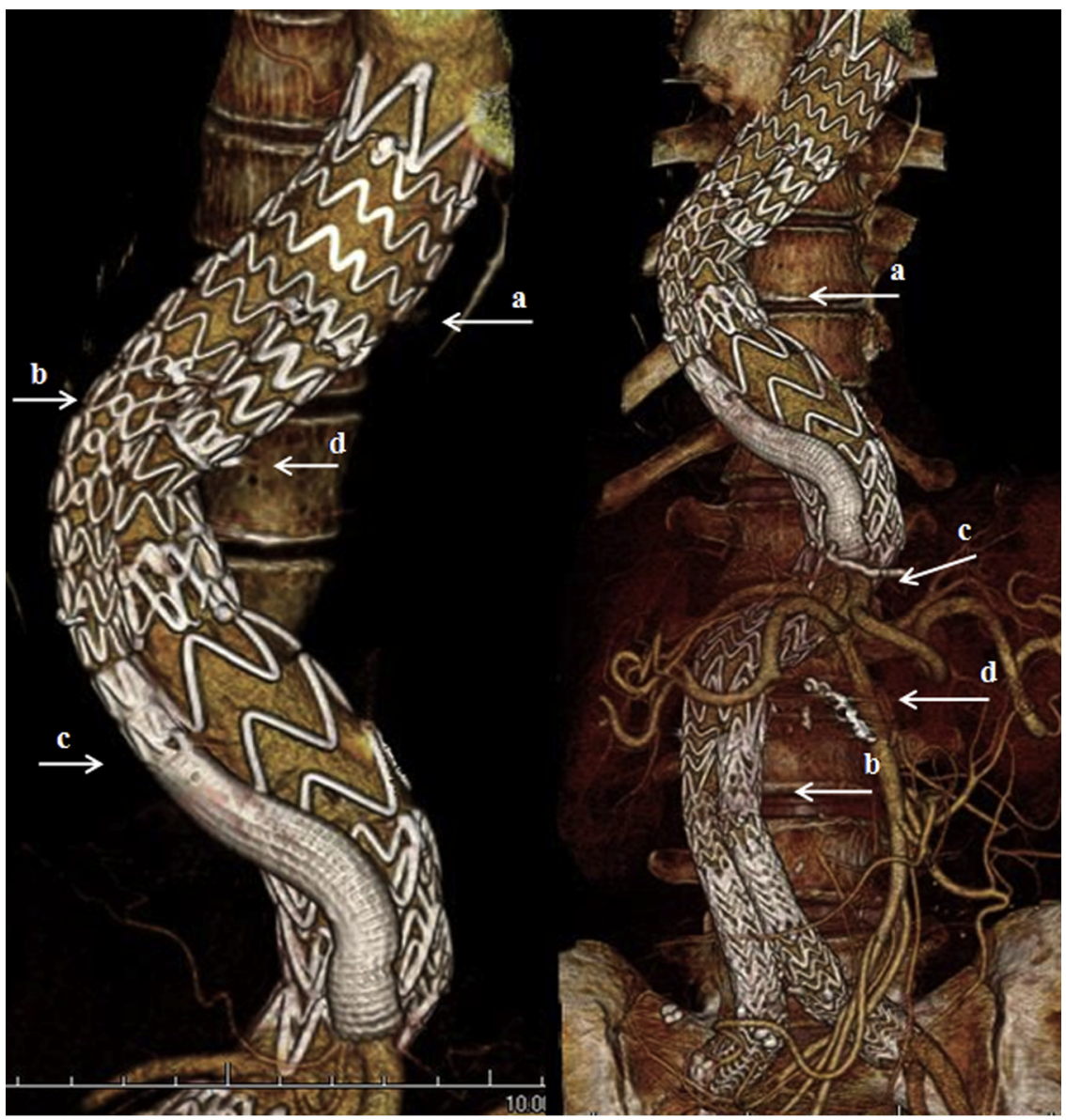

A

\section{B}

FIGURE 2. A, Immediate postoperative computed tomographic scan shows thoracic bifurcated endograft (a), straight Endurant endograft into the ipsilateral thoracic endograft limb $(b)$, Viabahn stent graft to revascularize the celiac trunk (c), and contralateral thoracic endograft limb extended to the superior mesenteric artery $(d)$. B, Late postoperative (4-year follow-up) computed tomographic scan shows thoracic endovascular aneurysmal exclusion $(a)$, infrarenal endovascular aneurysmal exclusion $(b)$, patent celiac trunk $(c)$, and patent superior mesenteric artery $(d)$.

greater than $30 \%$ was necessary. This could increase the risk of a coarctation similar to the congenital coarctation along the ipsilateral leg of the bifurcated endograft in the thoracic aorta.

Various types of endografts were selected after considering the vessels' tortuosity, the radial forces, and the diameter and length of the aneurysmal aorta. The high costs of the entire procedure were justified by the results obtained, especially at 4 years follow-up.

To our knowledge, this case 4 years ago was the first of TAAA treated with a bifurcated abdominal endograft deployed in the thoracic aorta. Recently, Kasirajan ${ }^{4}$ reported the parallel endograft octopus technique with 2 bifurcated endografts in the thoracic aorta.

In conclusion, in strictly selected patients, the off-label use of available materials by high-ability, skilled operators offers a valid therapeutic option for patients who would otherwise remain untreated. Long surveillance is necessary to detect potential complications or procedure failure and correct them promptly.

\section{References}

1. Liao JM, Bakaeen FG, Cornwell LD, Simpson K, Lemaire SA, Coselli JS, et al. Nationwide trends and regional/hospital variations in open versus endovascular repair of thoracoabdominal aortic aneurysms. J Thorac Cardiovasc Surg. 2012; 144:612-6.

2. Mastracci TM, Greenberg RK. Complex aortic disease: changes in perception, evaluation and management. J Vasc Surg. 2008;48(6 Suppl):17S-23S; discussion 23S.

3. Oderich GS, Fatima J, Gloviczki P. Stent graft modification with mini-cuff reinforced fenestrations for urgent repair of thoracoabdominal aortic aneurysms. J Vasc Surg. 2011;54:1522-6.

4. Kasirajan K. Branched grafts for thoracoabdominal aneurysms: off-label use of FDA-approved devices. J Endovasc Ther. 2011;18:471-6. Erratum in: J Endovasc Ther. 2011;18:A-5. 